\title{
"ESPAÑA QUE PERDIMOS, NO NOS PIERDAS"*. UNA LECTURA ENTRE LÍNEAS DE LA CORRESPONDENCIA PRIVADA DE LOS NIÑOS DE RUSIA
}

\section{Verónica Sierra Blas}

Universidad de Alcalá-SIECE-Grupo LEA**

* "España que perdimos, no nos pierdas" es un conocido verso del poeta Pedro Garfias (1901-1967). El poema lleva por título "Entre España y México" y fue compuesto a bordo del Sinaia, barco que le transportó a México junto a otros refugiados españoles en una de las expediciones más conocidas de la Historia del exilio. Véase P. Garfias, Poesía completa. Córdoba: Ediciones de la Posada / Ayuntamiento de Córdoba, (1989.

** Este trabajo se enmarca en el Proyecto de Investigación Cinco siglos de cartas. Escritura privada y comunicación epistolar en España en la Edad Moderna y Contemporánea (HAR2008-00874/HIST); en la Acción Complementaria V SIECE: Los avatares de la palabra escrita (2008-2009) (HAR2008-01075-E/HIST); y en la Acción Integrada Los lugares del escrito. Taller metodológico hispano-francés (HF2007-0063). 

Para Toga, que se marchó demasiado deprisa, pero nos regaló muchos días felices.

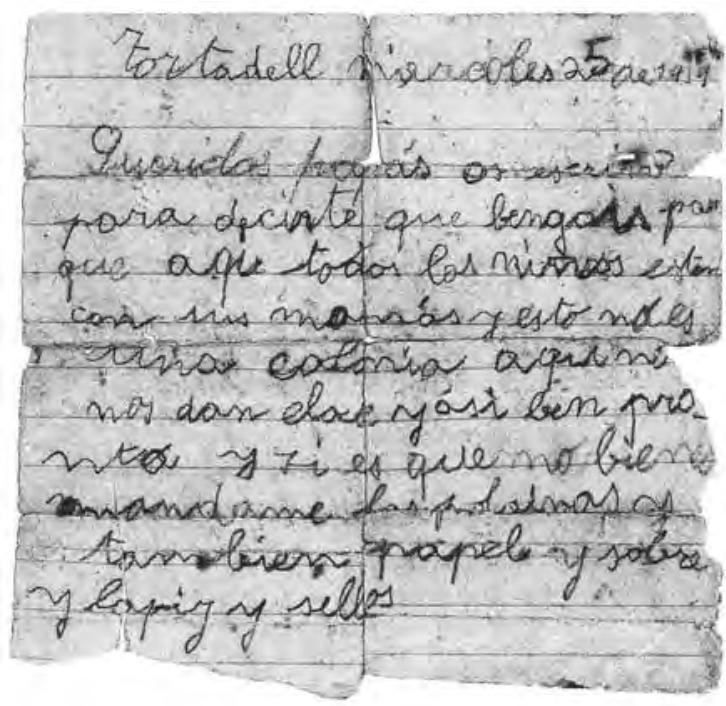

(Fig. 1)

Carta de Raquel Mejías Verdú a sus padres. Tortadell, 25 de [enero] de 1939. Archivo personal de Raquel Mejías Thiercelin, Cadente (Vaucluse, Francia).

Tortadell, miércoles 25 de [enero] de 1939.

Queridos papás: os escribo para decirte que bengáis, porque aquí todos los niños están con sus mamás y esto no es una colonia. Aquí no nos dan clase, y así ben pronto y si es que no bienes mándame las polainas y también papel y sobre[s] y lápiz y sellos. ${ }^{1}$

\footnotetext{
${ }^{1}$ Carta de Raquel Mejías Verdú a sus padres. Tortadell, 25 de [enero] de 1939. Archivo personal de Raquel Mejías Thiercelin, Cadenet (Vaucluse, Francia). No puedo dejar de agradecer a Raquel Mejías que me haya dejado emplear para mi trabajo este tesoro epistolar que lleva tantos años conservando y que tanto significa para ella.
} 
Raquel Mejías Verdú escribió esta carta a su madre desde el refugio de Tortadell un día antes de la caída de la capital catalana a manos de las tropas de Franco, el 26 de enero de 1939, cuando tenía 7 años. Este pequeño pedazo de papel (Fig. 1) quería ser una llamada de auxilio, pues sus padres habían decidido evacuarla de la ciudad algunos días antes junto a la hija de unos amigos a una colonia infantil, pero debido al caos reinante y a lo delicado de la situación, las niñas acabaron en un refugio que nada tenía que ver con lo que les habían contado sus mayores.

Allí no había escuela y todos los niños estaban acompañados de sus madres. Raquel se dio cuenta enseguida de que habían llegado allí por error y, por eso, escribió a su madre para que fuera a recogerla, para que la llevara de vuelta a casa. Pero Raquel sabía que la situación no era fácil, que era probable que su madre no acudiera en su busca, y ése presentimiento fue el motivo que le llevó a terminar su carta pidiéndole que le mandara ropa, papel, sobres, sellos y un lápiz, para abrigarse y no coger frío y para seguir manteniendo contacto con los suyos, dos necesidades que la niña creyó entonces básicas para subsistir en las condiciones en que se encontraba. Esta carta, sin embargo, nunca llegó a su destino y se convirtió en fiel compañera de exilio de su autora, quien todavía la conserva:

Aquel día de enero mi carta se quedó sin terminar. No sé por qué. No fue echada al correo ni llegó jamás a su destino, ciudad de Barcelona. Tampoco sé cómo he podido conservarla, después de tantos años y en medio de tantas vicisitudes. Se me traspapeló veinte veces, volviendo a aparecer dónde y cuándo menos me lo esperaba. En todos estos años en que me viene acompañando he tenido hacia ella sentimientos mitigados de cariño y de rencor. ${ }^{2}$

Raquel no recuerda por qué su carta no llegó nunca a enviarse. Y se sorprende de que, a pesar de todo lo vivido, la haya conservado, de que a día de hoy forme parte de su archivo personal. Después de vagar por varios refugios y vivir en condiciones extremas, Raquel y su amiga fueron acogidas por una maestra y residieron varios años en Contest, hasta que la madre de Raquel, ya exiliada en Francia, logró encontrarla gracias a un anuncio que publicó en el periódico L'Ouvre. Desde entonces reside en Francia y aquella carta que la acompañó día

${ }^{2}$ R. Duroux y R. Thiercelin, "Los niños del exilio: asignatura pendiente", en J. Cuesta y B. Bermejo (coords.), Emigración y exilio. Españoles en Francia, 1936-1946. Madrid: Eudema, 1996, pp. 167-82 (cita en p. 174). 
a día desde que salió de Tortadell ha recorrido el mundo como símbolo del exilio infantil de la Guerra Civil española.

Como la carta de Raquel, muchas cartas de niños evacuados durante la Guerra Civil española, que vivieron el exilio separados de los suyos, nunca llegaron a su destino y acabaron conservándose en lugares insospechados y sirviendo a objetivos inimaginables. Ninguna de ellas cumplió, por tanto, su fin primigenio: comunicar, mantener los lazos en la distancia, vencer la ausencia. En su interior reposa toda una historia de silencios que sólo una lectura entre líneas puede desvelar.

Este trabajo quiere incidir en la importancia que tiene reconstruir las condiciones de producción y los distintos caminos recorridos por los documentos hasta llegar a las manos de los investigadores para poder editarlos e interpretarlos correctamente y no confundir ni su forma ni su contenido, algo que en el caso de los testimonios escritos producidos por niños, siempre más frágiles y más susceptibles de ser manipulados y utilizados, se convierte en un riesgo todavía mayor. Para ello voy a elegir como escenario histórico las evacuaciones infantiles que tuvieron lugar durante la Guerra Civil española y, dentro de las mismas, las que tuvieron a Rusia como destino; y como objeto de estudio, empleando en su análisis e interpretación la metodología de la Historia de la Cultura Escrita, ${ }^{3}$ los dos centenares de cartas que los niños españoles evacuados a tierras rusas escribieron a sus padres y a algunos organismos asistenciales entre 1937 y 1938. Estas cartas, como la carta de Raquel, nunca llegaron a sus destinatarios y también se han conservado hasta nuestros días después de muchas vicisitudes, aunque no en archivos personales, sino en un archivo público, el Centro Documental de la Memoria Histórica de Salamanca. ${ }^{4}$

${ }^{3}$ Para una definición de la Historia de la Cultura Escrita remito a A. Petrucci, Historia de la escritura e Historia de la sociedad. Valencia: UV/Seminari Internacional d Estudis sobre la Cultura Escrita, 1998; del mismo autor, La ciencia de la escritura. Primera lección de Paleografía. Buenos Aires: FCE, 2002; F. M. Gimeno Blay, De las Ciencias Auxiliares a la Historia de la Cultura Escrita, Valencia: UV/Seminari Internacional d'Estudis sobre Cultura Escrita, 1999, pp. 14-16; id., "La Historia de la Cultura Escrita y la erudición clásica”, Cultura Escrita \& Sociedad, 1 (2005), pp. 124-42; A. Castillo Gómez, "El tiempo de la cultura escrita. A modo de introducción”, en id. (coord.), Historia de la Cultura Escrita. Del Próximo Oriente antiguo a la sociedad informatizada. Gijón: Trea, 2002, pp. 15-25; y del mismo autor, "La Corte de Cadmo. Apuntes para una Historia Social de la Cultura Escrita", Revista de Historiografía, 1: 2 (2004), pp. 89-98.

${ }^{4}$ Para un panorama completo y un análisis más en profundidad de este conjunto epistolar y de la escritura infantil en tiempos de guerra, remitimos al lector a nuestro libro Palabras huérfanas. Los niños y la Guerra Civil española. Madrid: Taurus, 2009. 


\section{UN VIAJE EN EL TIEMPO}

Las evacuaciones infantiles que tuvieron lugar como consecuencia de la Guerra Civil española constituyen, a día de hoy, uno de los éxodos infantiles más importantes de la primera mitad del siglo XX. Aunque las estadísticas varían mucho en función de las fuentes que se consulten, se puede afirmar que fueron más de 30000 los niños que salieron de España entre 1936 y 1939, cifra a la que habría que sumar, para comprender el desarraigo humano que provocó el conflicto, la importante participación infantil en el exilio del pueblo español que tuvo lugar en los últimos meses de la guerra (especialmente tras la caída de Barcelona el 26 de enero de 1939) y al finalizar la misma. Cerca de medio millón de españoles cruzaron entonces la frontera con Francia para ir a parar a los refugios habilitados y a los campos de concentración. ${ }^{5}$

Junto a la escasez de alimentos y medicamentos, que hacían del hambre y las enfermedades amenazas constantes para la población civil, especialmente para los niños, hubo una causa que fue determinante para que el Gobierno de la República crease organismos dedicados exclusivamente al cuidado y protección de la infancia, como la Delegación Central de Colonias (DCC) o el Consejo Nacional de la Infancia Evacuada (CNIE); así como para que iniciase, ya entre agosto y octubre de 1936, las campañas de evacuación infantil, primero hacia zonas seguras y alejadas de los frentes en el interior del país y luego hacia el extranjero, hacia los distintos países que se ofrecieron a acoger a la infancia española víctima de la guerra. Esa causa fueron los bombardeos a ciudades abiertas, ensayos de lo que ocurriría después a gran escala en la II Guerra Mundial, en los que perecieron gran cantidad de niños y cuyos efectos, tanto físicos como psíquicos, se tornaron en traumas que ni tan siquiera el paso del tiempo pudo curar.

La evacuación infantil tuvo como fines principales acoger a los niños españoles que se encontraban en situaciones de riesgo para ponerlos a salvo y para que pudieran reponerse de las secuelas de la guerra, además de procurar la continuación de su proceso de escolarización y suplir, en la medida de lo posible, el ambiente familiar y afectivo que la contienda les había robado, pues muchos de ellos se habían visto obli-

5 Para esta cifra puede consultarse el trabajo de A. Alted, "El exilio de los niños", en A. Alted, R. González y M. J. Millán (eds.), El exilio de los niños. Catálogo de la Exposición. Madrid: Fundación Pablo Iglesias/Fundación Largo Caballero, 2003, pp. 18-25. 
gados a separarse de los suyos o se habían quedado huérfanos. La acogida de los niños tuvo dos dimensiones principales, tanto dentro como fuera de España: por un lado, la familiar, pues se llevó a cabo por familias que se ofrecieron a adoptar a uno o a varios de los niños evacuados en sus propios hogares; y, por el otro, la colectiva, más extendida, en la que los niños fueron distribuidos y organizados en colonias subvencionadas por organismos oficiales y asistenciales y partidos políticos, donde se desarrollaba un régimen de vida comunitario y eran atendidos por un equipo de profesionales conformado por maestros, médicos y auxiliares. ${ }^{6}$

La acogida de los niños españoles en la Unión Soviética siguió esta segunda modalidad. Fueron 2895 los menores evacuados a Rusia entre el 17 de marzo de 1937 y finales de octubre de 1938, fechas en las que se desarrollaron la primera y la última de las cuatro expediciones oficiales que organizó el Gobierno republicano a ese país.7 A su llegada a la URSS los niños fueron divididos en grupos y repartidos en las distintas colonias o Casas de Niños (un total de 16) que el Narkompros (Comisariado del Pueblo para la Enseñanza) había creado específicamente para ellos, a veces rehabilitando edificios históricos inutilizados desde la Revolución de Octubre, en distintas provincias de la Federación Rusa y en Ucrania. Lo que, en un principio, se pensó iba a ser sólo una separación temporal de los suyos y de España se convirtió, sin embargo, para la mayoría, en toda una vida.

${ }^{6}$ Una aproximación a las colonias infantiles en la Guerra Civil española puede verse en R. Crego Navarro, "Las colonias escolares durante la Guerra Civil (1936-1939)", Espacio, Tiempo y Forma, Serie V, Historia Contemporánea, 2 (1989), pp. 299-328; y J. I. Cruz, "Colonias escolares y Guerra Civil. Un ejemplo de evacuación infantil”, en A pesar de todo dibujan. La Guerra Civil vista por los niños. Catálogo de la Exposición. Madrid: Biblioteca Nacional/ Fundación Winterthur, 2006, pp. 41-52. Para la modalidad de la adopción familiar es indispensable consultar el libro de J. J. Alonso Carballés, 1937. Los niños vascos evacuados a Francia y a Bélgica. Historia y memoria de un éxodo infantil, 1936-1940. Bilbao: Asociación de Niños Evacuados el 37, 1998.

${ }^{7}$ Para las evacuaciones infantiles a Rusia remito a las ya indispensables aportaciones de E. Zafra, R. Crego y C. Heredia, Los niños españoles evacuados a la URSS (1937). Madrid: Ediciones de la Torre, 1989; S. Castillo Rodríguez, Memoria, educación e historia: el caso de los niños españoles evacuados a la Unión Soviética durante la Guerra Civil española. Madrid: Universidad Complutense, 1999 (edición digital); A. Alted Vigil, E. Nicolás Marín y R. González Martell, Los niños de la guerra de España en la Unión Soviética. De la evacuación al retorno (1937-1999). Madrid: Fundación Francisco Largo Caballero, 1999; M. J. Devillard, A. Pazos, S. Castillo y N. Medina, Los niños españoles en la URSS (1937-1997): narración y memoria. Barcelona: Ariel, 2001; S. Castillo, Mis años en la escuela soviética. El discurso autobiográfico de los niños españoles en la URSS. Madrid: Los libros de la Catarata, 2009; e I. Colomina Limonero, Dos patrias, tres mil destinos: vida y exilio de los niños de la Guerra de España evacuados a la Unión Soviética. Madrid: Cinca, 2010. 


\section{EL CORDÓN UMBILICAL}

Durante el viaje a Rusia y una vez que se instalaron en las colonias que el Gobierno ruso había creado para ellos, los niños españoles tuvieron que cumplir con la promesa, realizada antes de partir, de escribir a casa, de mantener informados a los padres y familiares. Las cartas se convirtieron en la única manera de comunicarse con los suyos y de seguir manteniendo la relación con ellos, como si de una especie de cordón umbilical se tratara. Constituyeron, tanto para padres como para hijos, el alimento anímico, el sostén psicológico, que permitía superar la sensación de pérdida, la difícil vida en tiempos de guerra, la adaptación a un mundo nuevo y distinto. Igualmente, las cartas fueron el único medio de sostenimiento de los roles familiares, de control en la distancia. A pesar de la separación, los padres debían estar al tanto de lo que hacían sus hijos, eran los primeros a quienes éstos debían rendir cuentas, consultar y pedir permiso antes de emprender determinadas acciones o tomar decisiones importantes.

Se han conservado, como he señalado en líneas anteriores, alrededor de dos centenares de cartas escritas por los niños españoles evacuados a Rusia dirigidas a sus padres y a distintos organismos asistenciales, y dichas misivas podemos agruparlas en dos conjuntos epistolares diferenciados, pues sus fechas de producción, el contenido de las cartas y los caminos que siguieron varían enormemente y hacen de ellos dos grupos singulares, con unas características y peculiaridades determinadas, si bien ambos fondos, como veremos, tuvieron un mismo final.

El primer paquete epistolar está conformado por 134 cartas, fechadas entre el 23 de junio y el 4 de julio de 1937, cuyos autores son, en su mayoría, los niños santanderinos y vascos que formaron parte de la segunda de las expediciones a la URSS, organizada por el Gobierno Vasco del lehendakari Aguirre ante la ofensiva franquista sobre Vizcaya, que salió la madrugada del 13 de junio de 1937 del puerto de Santurce (Bilbao) y llegó a Leningrado el 22 de junio del mismo año, previa escala y cambio de barco (del Habana al Sontay) en el puerto de Pauillac (Burdeos). Los niños enviaron las cartas a sus direcciones particulares, a nombre de sus padres y familiares. En ellas narraban el embarque, cómo se desarrolló el viaje desde el País Vasco hasta tierras rusas, el trato que les dieron a bordo, el recibimiento del pueblo soviético a su llegada al puerto de Crostandt, las atenciones que les dispensaron los cuidadores y responsables en los primeros momentos, cómo les distribuyeron en 
grupos y las impresiones y experiencias vividas en el inicio de su estancia en el país de acogida. En este sentido, las misivas pueden ser leídas en su conjunto como un verdadero diario del viaje. Una vez llegaron a España las cartas, éstas fueron a parar al Negociado de Censura de la Comisaría General de Investigación Social, dependiente de la Dirección General de Seguridad (DGS), que tenía su sede en Valencia. A este primer paquete epistolar pertenecen las cartas de Linos Sáez, los hermanos Eugenio y Ambrosio, y Ángel Alonso:

Madre, el día que fuimos a embarcar es Sábado por la noche. No nos tocó asta la una de la mañana. Ende se despedió ustez de clamen [Carmen] y nosotros dos, avelina y Linos, nos tuvimos que poner en otra cola y después llamaban por números. Emprezaban así del 1 al 100, asta que llamaron del 1500 al 1600 que nos tocó a avelina, a linos, a los hijos de [Nebreda], a los hijos de mi padrina. ${ }^{8}$

El día 12 de junio embarquemos en el Habana. Al día siguiente salimos del muelle de Santurce a las 5 de la madrugá y a las 3 de la tarde vimos el faro del puerto de Burdeos y llegamos a Burdeos a las 6 de la tarde. Vino bastante público a recibir[nos] y allí pasemos 2 días. Y el martes a la tarde desembarcamos a otro barco Francés que se llama Sontay y a las 7 de la noche salimos del para Rusia, y como no se ve nada más que mar y cielo es cosa muy triste. Y el miércoles a la noche pasemos Bélgica y Inglaterra, dentro de 3 días llegamos a Alemania y pasemos una marea muy mala, y dentro de 5 días llegamos a Leningrado, y estos 8 días no vimos nada más que unos barcos mercantes. Llegamos a Leningrado el martes a la noche, nos recibieron muy bien y hubo mucho público.?

Querida madre: te escribo cuatro letras para decirte que estoy bien, hemos llegado a Crostan [Kronstadt], Leningrado, el 22 de Julio. Nos han hecho un gran recibimiento,

${ }^{8}$ Carta de Linos Sáez dirigida a sus padres y hermanos. Leningrado, 24 de mayo de 1937. Centro Documental de la Memoria Histórica de Salamanca (CDMH), pieza Político Social (PS) de Bilbao, caja 5, carpeta 14, documento 11. Todas las cartas que se citan en este trabajo han seguido una transcripción paleográfica, respetándose en todo momento su ortografía original. Únicamente se han modificado su puntuación y acentuación, que han sido actualizadas. Cualquier restitución del texto o intervención realizada por mi parte con el fin de aclarar alguna información contenida en el mismo ha sido convenientemente señalada entre corchetes [].

${ }^{9}$ Carta de Ambrosio y Eugenio dirigida a sus padres y hermanos. Leningrado, 23 de junio de 1937. CDMH, PS Bilbao, caja 5, carpeta 13, documento 40. 
algo grande, nos han recibido con banderas y todo. Desembarquemos al día siguiente. Nos dieron limonada, luego fuimos en auto y fuimos cantando la internacional y así sucesivamente y luego bagemos del auto y fuimos y fuimos a una casa donde nos dieron pan con leche y luego nos llebaron a otra casa donde nos sometieron a un reconocimiento de manos, vista y boca. Luego nos hicieron dar una ducha, después de la ducha nos dieron de comer pan con leche, pan con margarina y vaso grande de chocolate. Después nos dieron pantalón, calzoncillo, camisa y camiseta, un par de calcetines y sandalias y luego fuimos otra vez al auto y nos llevaron a una colonia [...]. ${ }^{10}$

El segundo paquete epistolar lo componen 91 cartas, escritas entre mediados de 1937 (la más temprana es del 30 de agosto) y mediados de 1938 (la más tardía corresponde al 5 de julio), por los niños de esa misma expedición, junto a algunos de la tercera, dirigida por Pablo Miaja, que se puso en marcha ante la ofensiva franquista sobre Santander y Asturias. Partió a bordo del carguero francés Deriguerina desde el puerto de El Musel (Gijón) la madrugada del 24 de septiembre de 1937, pocas semanas antes de la caída de la ciudad, bajo la responsabilidad de la Consejería de Instrucción Pública dependiente del Consejo Provincial de Asturias y León. Después de varios trasbordos, realizados en Saint Nazaire (Kooperatsia) y Londres (Feluks Dzerzhinsky), el grupo llegó a Leningrado el 4 de octubre de 1937.

Estas cartas fueron enviadas, en su mayoría, a la Delegación de Asistencia Social de Euzkadi en Barcelona, pues la capital catalana se había convertido desde agosto de 1938 en el centro postal republicano por excelencia. Toda la correspondencia que se enviaba o recibía del extranjero se inspeccionaba allí. ${ }^{11}$ El motivo de este cambio de destino es que en estas fechas gran parte de la población del Norte de España ya había sido evacuada y muchos de los domicilios particulares habían quedado vacíos. Fue en este momento cuando establecer contacto epistolar empezó a ser una tarea difícil. Un buen número de los niños evacuados no sabían dónde se encontraban sus padres y habían dejado de

${ }^{10}$ Carta de Ángel Alonso a su madre. Leningrado, 24 de junio de 1937. CDMH, PS Bilbao, caja 4, carpeta 11 , documento 8 .

${ }^{11}$ Para los avatares del correo durante la Guerra Civil española remito a F. Aracil, La Guerra Civil en la Historia Postal. Madrid / Barcelona: Edifil, 1996; y a J. García Sánchez, "La correspondencia de los españoles en Francia (1936-1946)”, en Cuesta y Bermejo (coords.), Emigración y exilio, pp. 330-43. 
tener noticias suyas, por lo que, para contactar con sus familias e indagar sobre su paradero, recurrieron a este organismo.

Las misivas enviadas a Barcelona responden a dos modalidades diferenciadas: unas (64 en total) van dirigidas a los padres y familiares y constituyen una verdadera crónica de la vida cotidiana de los niños en sus primeros meses en la Unión Soviética, aportando numerosos datos acerca de la organización de las Casas, de la alimentación, de la educación y de las actividades extraescolares y, en general, de todo lo que los pequeños evacuados hacían en tierras rusas. Estas cartas dirigidas a los familiares fueron enviadas a la Delegación antedicha para que desde allí se repartiesen a sus destinatarios, cuyo lugar de residencia, al ser refugiados, los niños desconocían. Otras (tan sólo 10) son peticiones que los menores dirigen directamente a las autoridades republicanas para que les ayuden a encontrar a sus familias.

Valgan como ejemplo de la primera modalidad las cartas que escribieron los niños Enrique Undiano y Lucio Rueda, en las que narran el régimen de vida que realizan, el primero en la Casa de Niños de Moscú, en período estival, y el segundo en la de Odessa, ya en el duro invierno ruso, para el que los cuidadores y responsables les prepararon a conciencia:

Aquí estamos como en jauja. Comemos cuatro veces al día. Nos levantamos de la cama, nos labamos y vamos a almorzar. Nos suelen dar 2 cachos de pan con mantequilla y otro con queso y una taza o un baso de chocolate. Después nos vamos a un bosque que hay muy cerca y nos dan un bollo y una onza de chocolate o un bollo y tres alberchigos. Estamos allí hasta el mediodía y después vamos a la colonia, una ducha y a comer. Nos dan muy buena comida y todos los días diferente. Comemos y vamos a echar la siesta. Nos levantamos y a merendar. Solemos merendar pan, mantequilla, fresas, chocolate hecho y pan todo [el] que queremos. Después a jugar y a cenar. Nos dan muy buena cena y todos días diferente, además siempre con postre. ${ }^{12}$

A nosotros nos van a dar esquíes y trineos pa la nieve, porque aquí cubre mucho, la nieve cubrirá cerca de medio metro, y nos han dicho que eso no es nada, que aquí donde esta-

${ }^{12}$ Carta de Enrique Undiano dirigida a su madre y hermana. Moscú, 30 de junio de 1937. CDMH, PS Bilbao, caja 5, carpeta 14, documento 22. 
mos nosotros nos dicen que cubrirá un metro, y en Moscú metro y medio, y que llegar[á] el frío hasta 38 gragos lo más, y en Odessa que es donde estamos nosotros a 24 g. lo más, y por eso nos van a dar esquíes y trineos para los pequeñitos como para la Consuelo. A los pequeños les han dau unos trajes muy bonitos y que abrigan mucho, y a nosotros nos van a dar 3 trajes, uno para los días de fiesta, que es muy bueno, y 2 para los días de lavor, uno de pana, y otro también muy bueno. También nos han dau 2 pares de medias y chanclos y botas, y nos van a dar creo que botas catiuscas o otra cosa nueva. ${ }^{13}$

En medio de la caótica situación provocada por las evacuaciones no era sencillo dar con los familiares desaparecidos. Las personas que participaban en este proceso de búsqueda realizaban labores muy diversas para la consecución de tan importante objetivo. Algunas cartas pasaban a la Oficina de Estadística e Información, donde se buscaban los nombres de los familiares en listas interminables. Tras este paso, que si era negativo se saldaba con un sello en el que ponía "No consta» o un simple "No» manuscrito, uno de los recursos más empleados fue publicar el nombre de la persona o personas buscadas en las páginas de los periódicos. Por eso, en los sobres y, en ocasiones, en las propias cartas puede leerse, escrito normalmente a lápiz, la anotación «Prensa», que por lo general iba acompañada de la fecha en la que se había publicado el anuncio. Así puede verse en la siguiente carta de Martín Peña, escrita desde Odessa el 8 de enero de 1938, en la que el niño pide ayuda para encontrar a su madre y su hermano, de quienes hace meses que no recibe noticia alguna (Fig. 2). ${ }^{14}$

${ }^{13}$ Carta de Lucio Rueda Maestro dirigida a su hermano Victoriano. Odessa, 6 de enero de 1938. CDMH, PS Santander, serie "O", caja 51, carpeta 7, documento 65.

${ }^{14}$ Carta de Martín Peña dirigida a las autoridades republicanas de la Delegación de Asistencia Social de Euzkadi en Barcelona. Odessa, 8 de enero de 1938. CDMH, PS Bilbao, caja 206, carpeta 8, documento 1. 


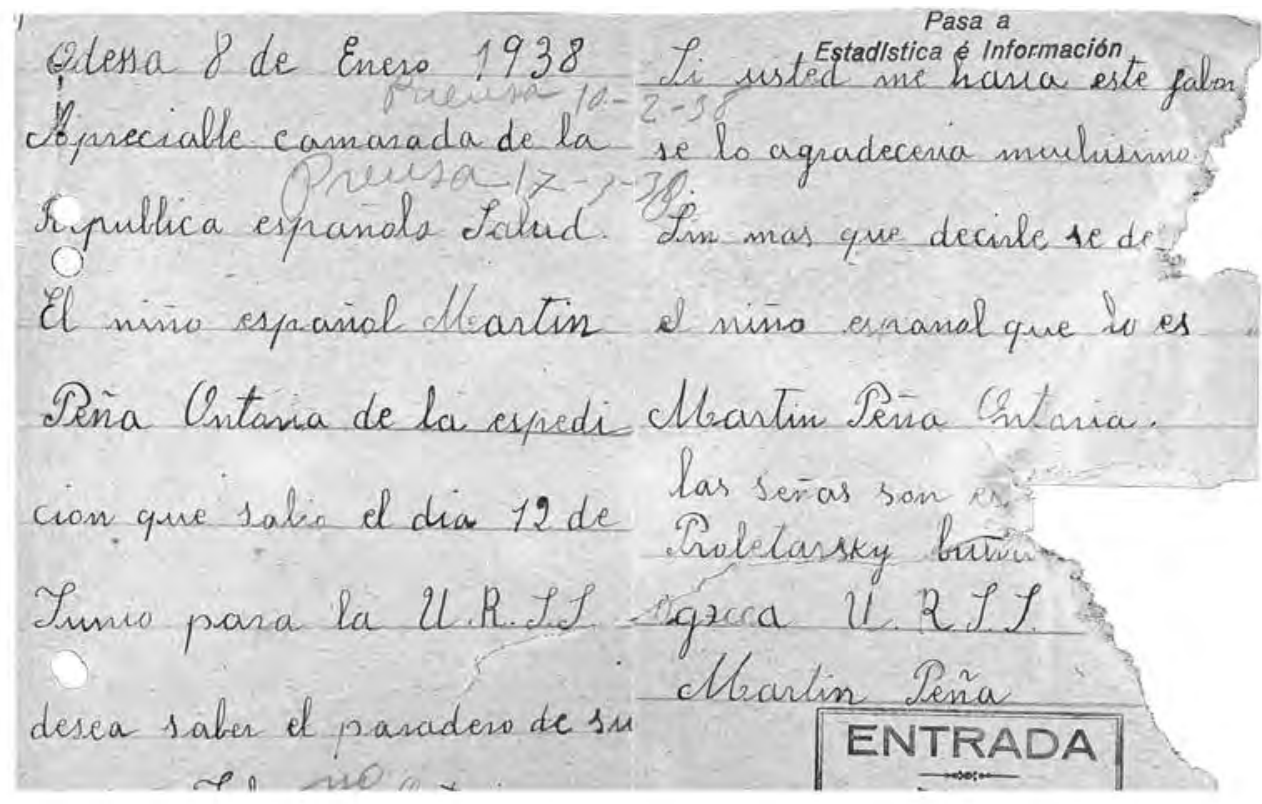

(Fig. 2)

Carta de Martín Peña Ontoria dirigida a las autoridades republicanas para solicitar indaguen el paradero de sus padres. Odessa, 8 de enero de 1938. Centro Documental de la Memoria Histórica de Salamanca, pieza Político-Social de Bilbao, caja 206, carpeta 8, documento 1.

\section{LEYENDO ENTRE LÍNEAS}

Aunque, a simple vista, podamos pensar que las cartas que componen estos dos paquetes epistolares conservados en el Centro Documental de la Memoria Histórica de Salamanca sólo nos hablan de la experiencia de la evacuación y de la vida cotidiana de los niños españoles en el país soviético, una lectura entre líneas nos lleva a intuir otras informaciones que, si bien no aparecen de forma explícita, quedan reflejadas de alguna manera o pueden salir a la luz gracias a otros testimonios que, contemporáneos o no, sirven de complemento a la correspondencia y que son muy útiles para reconstruir este u otros episodios históricos, tales como informes, entrevistas orales o diarios, memorias y autobiografías escritos por los propios protagonistas. Estos silencios, estas informaciones no 
escritas por las manos infantiles, son precisamente las que debemos desvelar para poder estudiar e interpretar correctamente este tipo de documentación.

Después de "leer entre líneas", es decir, de analizar las cartas que los niños españoles escribieron a sus familiares durante su exilio en Rusia más allá del contenido, de lo que percibimos a simple vista y de los objetivos que sus propios autores quisieron con ellas cumplir, pueden distinguirse, al menos, tres tipos de "silencios": el corsé impuesto por el control de la correspondencia por parte de los cuidadores de los menores, primero, y por la censura postal del momento, después; el uso propagandístico que se hizo de estos testimonios infantiles; y, por último, los fines encubiertos de su conservación en el Centro Documental de la Memoria Histórica de Salamanca.

Dichos silencios podemos reconstruirlos detectando las transformaciones que provocan en estos documentos, en lo que a sus fines originarios se refiere, las distintas intervenciones de determinados agentes externos. En otras palabras: las cartas de los Niños de Rusia que han llegado hasta nosotros contienen la huella de la manipulación de la que fueron objeto por parte de los adultos, quienes, sirviendo a sus intereses, desvirtuaron lo que en un inicio podríamos considerar una documentación ingenua y espontánea, libre de intenciones ideológicas y propagandísticas, por haber sido producida por unos niños que lo único que querían era comunicarse con los suyos y que la guerra que ensangrentaba su país terminara de una vez para poder volver a casa, recuperando así la vida que habían dejado atrás sin elección, obligados por las circunstancias que les tocó vivir.

\subsection{El corsé de la censura}

El intercambio epistolar entre padres e hijos fue uno de los aspectos a los que los responsables de las evacuaciones dedicaron más atención en lo que al régimen de vida de los niños en las colonias y en las distintas casas de acogida se refiere. Los cuidadores de los niños debían procurar que la relación postal entre ambas partes fuera regular y que ni a unos ni a otros les faltase este alimento anímico que representaban las noticias que las cartas portaban. Se llegó incluso a regular oficialmente esta obligación de procurar que se estableciera una correspondencia estable, como demuestra la normativa que el Departamento de Asistencia Social del País Vasco ela- 
boró para las colonias infantiles establecidas en Francia, en las que todos los que estuvieran al cuidado de los niños debían ocuparse de que éstos se pusieran "en relación postal con los padres", enviando al citado Departamento "la relación nominal de los niños a su cargo, así como la dirección de la localidad en la que se hallan". ${ }^{15}$

Igualmente, en el caso de los niños acogidos por familias, uno de los requisitos que los padres adoptivos debían cumplir era el de comprometerse a que los menores no olvidaran sus orígenes y mantuvieran, en la medida de lo posible, el contacto con sus padres biológicos. Así, Gregorio, un niño evacuado a Bélgica con 9 años, recuerda cómo la familia que le acogió le obligaba a escribir a España, tarea cuyo incumplimiento acarreaba algunas reprimendas y castigos:

Me decían: "Hay que escribir a España, si no, no sales a jugar". Y eso de no salir a jugar, era como la cárcel. Ponías cuatro letras, pero estaba bien que me obligaran. De mayor lo reconoces, porque ibas perdiendo y olvidando a los padres, ibas olvidando. ${ }^{16}$

El hecho de que los responsables de los niños tuvieran como obligación que éstos mantuvieran el contacto escrito con sus respectivas familias no debe, sin embargo, hacernos perder de vista otras realidades. Si bien los cuidadores de los menores se preocuparon de que éstos siguieran escribiendo a casa, ésta no fue su única labor en lo que al mantenimiento de las relaciones epistolares entre padres e hijos se refiere. Quienes estaban a cargo de los niños debían, además de incentivar la práctica epistolar, controlar y supervisar la escritura de las cartas, que antes de ser enviadas debían pasar por las manos de quienes estaban encargados de dicha tarea. Así, por ejemplo, Lola Arroitia, una de las maestras que trabajó con los niños españoles en la colonia francesa Donibane Garazi, confesó al historiador Gregorio Arrien que ella fue la encargada de censurar tanto la correspondencia que escribían los niños como la que recibían de sus casas:

Cuando los niños escribían sus cartas a casa espontáneamente, el maestro se encargaba de leerlas y depositarlas en el correo [...]. A veces, el pedagogo añadía al pie de página esta nota significativa: «No se preocupe de su hijo, yo cuidaré del mismo. La maestra».

\footnotetext{
${ }^{15}$ Alonso Carballés, 1937. Los niños vascos evacuados, p. 89.

${ }^{16}$ Id., p. 331.
} 
Las cartas recibidas de casa eran igualmente leídas primero por el maestro, por la simple precaución de evitarles cualquier noticia que pudiera afectar a los niños desagradablemente. Por lo general no hubo necesidad de disimular el contenido y las noticias que se enviaban a través de las cartas. ${ }^{17}$

En el caso que nos ocupa no es posible conocer qué tipo de informaciones se ocultaron a los niños, pues no se han conservado (o al menos no se han encontrado) las cartas que los padres escribieron a sus hijos durante su exilio en Rusia (muchas seguramente estarán en manos particulares). Si es posible, sin embargo, advertir algunos rastros de este tipo de censura preventiva en las propias cartas de los niños, donde en ocasiones vemos cómo los adultos hicieron desmentir a los pequeños evacuados determinadas informaciones escritas o incluso tacharon frases que no convenía fueran leídas por los padres. Ambos aspectos muestran que, al igual que en otras colonias infantiles, en las Casas de Niños de la URSS la escritura epistolar fue vigilada de cerca y constituyó una actividad controlada por parte de los adultos encargados del cuidado de los menores.

Basten dos ejemplos. Cuando la persona responsable de cursar la correspondencia de Antonio Ochoa vio que éste había escrito a sus padres en su carta del 24 de junio de 1937 que al llegar a la Unión Soviética les "dieron ropa nueva y la maleta no nos la dieron, nos la tiraron al mar y las botas también", le pidió que corrigiera esta información. El niño aceptó la sugerencia, pues al final de la carta enmienda lo escrito advirtiendo: "Queridos padres: las ropas que hemos traído de España no nos las tiran ni las queman, sino que la guardan para cuando volvamos a ésa". ${ }^{18}$ Algo parecido se observa en la carta del niño Santos Cadabiz, quien escribía también a sus padres para notificarles su llegada a Leningrado y narrarles su viaje. El niño, al hacer referencia al reparto de juguetes que tuvo lugar a bordo del buque Sontay entre los tripulantes, afirma que "En Francia ycimos enbarque de[l] Avana al Sontay. En el barco las [¿camaradas?] no nos dieron ni juguetes ni libros. Los juguetes fueron para los [¿jantifascistas]? que tenían su [¿̨madre?] y [ilegible] y los demás sin nada”. ${ }^{19}$ San-

${ }^{17}$ G. Arrien, La generación del exilio. Génesis de las escuelas vascas y las Colonias Escolares (1932-1940). Bilbao: Colectivo Pedagógico ONURA, 1983, pp. 283-84.

${ }^{18}$ Carta de Antonio Ochoa dirigida a sus padres. Rusia, 24 de junio de 1937. CDMH, PS Bilbao, caja 5, carpeta 13, documento 43.

${ }^{19}$ Carta de Santos Cadabiz dirigida a su madre, a sus hermanos y a su prima. Sin lugar, sin fecha. CDMH, PS Bilbao, caja 5, carpeta 11, documento 30. 
tos no rectificó su afirmación en lo que queda de carta, pero no fue necesario, ya que él mismo o alguna otra persona tachó completamente la frase anterior, haciéndola desaparecer de la misiva.

En ambos casos, quienes supervisaron estos escritos se cuidaron de que en las cartas no se transmitieran noticias que pudieran intranquilizar a los padres o dañar la imagen positiva de las evacuaciones infantiles, de quienes estaban a su mando y del país de acogida. Éste era el fin último de dicho control, de la vigilancia a la que fueron sometidas las cartas que los niños mandaban a sus casas. En el último ejemplo expuesto, además, dada la insistencia tanto de Inglaterra como de Francia en la neutralidad ideológica que debía guiar las expediciones infantiles como requisito para subvencionar parte de los gastos que éstas conllevaban, la afirmación inocente del niño podía traer consecuencias tremendas en caso de caer la carta en manos inoportunas.

Aparte de la censura previa que ejercían en las colonias quienes estaban al cuidado de los menores evacuados, las cartas de éstos debían pasar aún otro filtro antes de llegar a manos de sus destinatarios, el de la censura postal. Todas las cartas procedentes o dirigidas al extranjero pasaban por la censura, al menos desde el 15 de agosto de 1936, fecha en la que el Servicio Internacional de Correos publicó la Orden Ministerial de Comunicaciones destinada a regular este aspecto. En dicha Orden se decía expresamente que todas aquellas misivas que no tuvieran el sello de los censores serían retenidas y devueltas a las oficinas encargadas de la censura para ser sometidas a examen: "Si alguna oficina recibiese, aunque no sea de cambio, correspondencia epistolar sin que previamente hubiese sido sometida a la censura, deberá abstenerse de entregarla”. ${ }^{20}$ Igualmente, otra Circular del Servicio Internacional de Correos de 26 de noviembre de 1938 advertía que las cartas y tarjetas postales, para llegar a su destino, debían poderse leer sin dificultad, para facilitar la tarea de los censores: "El texto tanto de las cartas como de las tarjetas postales deberá estar escrito en lenguaje claro y de forma legible". ${ }^{21}$

${ }^{20}$ Circular del Servicio Internacional de Correos. Madrid, 15 de agosto de 1936. Cfr. E. L. Heller, Marcas utilizadas por la censura republicana durante la Guerra Civil española. Madrid: Lindner Filatélica Ibérica, 1995, p. 35.

${ }^{21}$ Circular del Servicio Internacional de Correos en cumplimiento del artículo 6 del Decreto del Ministerio de Comunicaciones y Transportes de 22 de agosto de 1938. Barcelona, 26 de noviembre de 1938. Cfr. Id., p. 40. 
La censura, con sus normas y prohibiciones, fue uno de los impedimentos por excelencia para hacer efectiva la comunicación entre los niños evacuados y sus familias, especialmente una vez que la guerra concluyó y Franco se hizo con el país. ${ }^{22}$ Retrasó la entrega de las cartas, impuso un corsé a la espontaneidad infantil y condicionó fuertemente las relaciones epistolares, eliminando informaciones o tachando partes de las misivas.

Los tachones negros de los censores confundían y, a la vez, impresionaban a los niños. A veces incluso hacían imposible la tarea de leer las cartas. Pero no siempre la censura intervino de forma tan evidente. Su presencia, por lo general, era mucho más sutil. Los niños sabían qué podían y qué no podían escribir en sus cartas, y se cuidaban de respetar esta normativa no escrita, sobre todo por las consecuencias que podía traerles a los suyos trasladar determinadas informaciones. El uso de palabras con doble sentido, claves secretas y mensajes cifrados fueron recursos de los que padres e hijos se sirvieron para poder comunicarse con libertad. Como escribía en sus memorias inéditas una mujer evacuada a la URSS con 13 años, "en las cartas poníamos mucho cuidado [...], no decíamos mucho en las cartas pero a veces en forma entrevelada nos decíamos cosas que otros no lo hubieran comprendido". ${ }^{23}$

Junto a esta "escritura entrevelada" hubo muchas otras estrategias que tanto los niños españoles evacuados a Rusia como sus familiares inventaron para poder establecer contacto escrito, cruzar informaciones no permitidas y no poner en peligro a nadie, como, por ejemplo, firmar las cartas con nombres falsos, enviar la misma carta varias veces a direcciones distintas por si alguna llegaba sin pasar por las manos de los censores o hacer que la misiva fuera a parar a América o a Francia a manos de algún familiar o conocido que, a su vez, lograra hacerla llegar a España sin pasar por la censura y sin levantar sospechas. Eso hizo Isabel Argentina Álvarez Morán, quien fue evacuada a Rusia a los 12 años junto a su hermana Carmen, de 5, en la expedición que salió de Gijón en septiembre de 1937. Meses antes las niñas se habían quedado huérfanas de madre, y su padre, llamado a filas, consintió enviarlas a la URSS, después de las recomendaciones de los responsables del refugio Rosario Acuña, donde éstas residían en la ciudad asturiana. Isabel recuerda cómo las cartas que escri-

\footnotetext{
22 Para la censura postal del primer franquismo remito a E. L. Heller, Marcas utilizadas por la censura postal nacional de 1936 a 1945. Madrid: Lindner Filatélica Ibérica, 2000.

${ }^{23}$ Testimonio recogido en Castillo Rodríguez, Memoria, p. 458.
} 
bían a su padre las mandaban primero a su tío Julián, que vivía en Argentina, asegurándose así de que no le trajeran problemas de ningún tipo:

Mantenía correspondencia con mi padre a través del tío José, que aún vivía en San Julián (Argentina). Esto comenzó pensado cómo iba yo a tener noticias de mi padre estando Franco en el poder y corriendo el riesgo de que fueran a cometer represalias contra él por tener a sus hijas en la URSS. Un día se me ocurrió la idea de escribir al alcalde de San Julián, porque no sabía la dirección del tío José. Y resultó fabuloso, cuando menos lo esperaba recibí carta de los tíos, y luego comencé a través de ellos a escribir a nuestro padre, hasta el punto de que llegó a pensar que vivíamos allá [...]. Lo más importante era que nuestro padre se sintiera feliz de saber de nosotras donde quiera que estuviéramos. Más tarde empecé a escribirme con la tía Feliciana, que vivía aún en Francia, en el exilio. ${ }^{24}$

Pero, quizás, la vía más efectiva puesta en práctica por los niños para poder hacer llegar noticias no permitidas a sus padres fue aprovechar el retorno de algunas personas que estaban de paso en la URSS y que podían llevar en mano las cartas, sin necesidad de pasar los controles establecidos. Ésa fue la tarea que trajo consigo Rafael Miralles, quien pasó varios meses en Rusia como agregado de prensa de la Legación Cubana en Moscú, después de haber combatido en la guerra española en las filas del Partido Socialista Unificado de Catalunya (PSUC) y de las Brigadas Internacionales. Estando allí, pocos días antes de volver a Cuba, visitó una Casa de Niños ubicada en Tsaratovskaia, y una niña le pidió que llevara una carta a sus padres, exiliados en el continente americano:

El primer encuentro con un grupo de ellos [de niños y niñas españoles] lo tuve en la colonia escolar de Tsaratovskaia. Había ido a hacer una visita a unos amigos rusos en esta aldea, próxima a Moscú [...]. Una niña, al enterarse de que marchaba a América, me preguntó si podría llevar una carta a sus padres, y al contestarle afirmativamente penetró en la "dacha" (casa de campo) para regresar cuando me hallaba a punto de irme, deslizándome en las manos una carta y desapareciendo seguidamente, con visible temor de ser vista. ${ }^{25}$

${ }^{24}$ I. A. Álvarez Morán, Memorias de una niña de la guerra. Gijón: Ayuntamiento de Gijón, 2003, p. 195.

${ }^{25}$ R. Miralles, Españoles en Rusia. Madrid: Ediciones y Publicaciones Españolas, 1947, pp. 204-05. 


\subsection{Colaborando con la propaganda}

De entre los países que se ofrecieron a acoger a los niños españoles, el que más número atendió fue Francia (20 000), seguido de Bélgica (5000), Inglaterra (4000), Rusia (2895), México (463), Suiza (430) y Dinamarca (100). Otros países, como Noruega y Suecia, aunque no mantuvieron menores en su territorio, también aportaron personal, materiales y dinero para la organización de las expediciones y el funcionamiento de distintas colonias en España y en otros lugares. ${ }^{26}$

Si hubiera que destacar un hito entre las causas que determinaron que la política de la República a favor de la evacuación infantil tuviera repercusión en la opinión pública internacional y determinara el apoyo a la misma de otros países, habría que señalar, sin duda, el trágico bombardeo que arrasó la villa vasca de Guernica el 26 de abril de 1937. A partir de ese momento, las salidas de los niños fueron precedidas de importantes campañas de propaganda, cuyo fin no era otro que mostrar los horrores del pueblo español, especialmente de los niños, más indefensos y desamparados, que bombardeados y perseguidos necesitaban huir del país para poder salvarse. La prensa y la cartelística hicieron que lemas como "Ayudad a los niños de España" o "Salvad a la infancia española" calaran hondamente en todo el mundo. La efectividad del mensaje de ayuda y protección a la infancia se reflejó en una especie de "consenso emocional" a favor de las evacuaciones. ${ }^{27}$

Para mantener dicho consenso y el clima favorable a la salida de los niños del país era imprescindible transmitir a las familias tranquilidad y seguridad, y

\footnotetext{
${ }^{26}$ Para una aproximación a las evacuaciones infantiles que tuvieron como destino estos países remito a los trabajos de Y. Cloud, The Basque children in England. An account of their life at North Stoneham Camp. Londres: Victor Gollancz Ltd., 1937; D. Legarreta, The Guernica Generation. Basque Refugee Children of the Spanish Civil War. Reno: University of Nevada Press, 1984; D. Pla Brugat, Los niños de Morelia. México DF: INAH, 1985; G. Arrien, Niños vascos evacuados en 1937. Album histórico. Bilbao: Asociación de Niños Evacuados el 37, 1998; P. Marques, Les enfants espagnoles réfugiés en France (1936-1939). París: Edición del autor, 1993; R. Duroux, "Alice, Nini et les autres... La Norvège au secours des réfugiés espagnols, 1936-1945”, en Exils et migrations ibériques au XIXe siècle, 2 (1996), pp. 63-95; E. Labajos Pérez y F. Vitoria-García, Los niños españoles refugiados en Bélgica, 1936-1939. Valencia: Asociación de los niños de la guerra de Namur, 1997; S. Farré, "Exilés et internés espagnols en Suisse. Relations bilatérales hispano-siusses (1936-1946)", en M. Cerutti, P. Huber y S. Guex (eds.), La Suisse et la Espagne: de la République à Franco (1936-1946). Lausanne: Antipodes, 2001, pp. 107-24; y E. Pons Prades, Los niños republicanos. El exilio. Madrid: Oberón, 2005.

${ }^{27}$ Castillo Rodríguez, Memoria, p. 107.
} 
demostrar, de cara al ámbito internacional, el desarrollo modélico de las evacuaciones. Mientras que la propaganda republicana se centró en proyectar esta imagen positiva de la evacuación infantil para asegurar su continuidad, la propaganda franquista empleó todos sus esfuerzos en denunciar, cuestionar y desacreditar las evacuaciones, tildándolas de «robos de niños» y de acciones forzadas o impuestas, y repatriar a los menores a la «España madre», preocupada por sus hijos y ansiosa de recuperarlos.

Esta campaña propagandística del Gobierno franquista tuvo su punto culminante en la creación, mediante Orden de 1 de julio de 1938, de la Delegación Extraordinaria de Repatriación de Menores (DERM), dependiente en un principio del Ministerio de Asuntos Exteriores y, desde junio de 1941, de la Delegación Nacional del Servicio Exterior de Falange Española Tradicionalista y de las Juntas de Ofensiva Nacional-Sindicalistas (FET y de las JONS). ${ }^{28}$ Así, por ejemplo, en el folleto Cómo trata la Nueva España a los niños de la zona roja, editado en Pontevedra en 1937, se intentaba subrayar el buen trato que el bando franquista daba a los niños republicanos en contraste con "la bochornosa conducta del titulado Gobierno marxista de Valencia que los expatria a Rusia, México y otros pueblos de análoga insolvencia moral":

Entre las medidas adoptadas por los marxistas, relacionadas con la desdichada población infantil, hay una verdaderamente cruel que recogerá la Historia como triste testimonio de la barbarie de estas gentes. Los niños, en grandes manadas, sin respeto a los sexos ni a las edades, son arrancados de sus hogares y lanzados a Rusia y a otras latitudes que no tienen la menor analogía moral con España. Sus normas pedagógicas, tan cacareadas, no les permiten hacer con las pobres criaturas más que eso. Meterlas atropelladamente en los buques extranjeros, burlando casi siempre el sagrado derecho de los padres, con cuya autoridad no se cuenta, y entregarlos a las exóticas influencias de otros climas, de otras

28 J. J. Alonso Carballés y M. Mayoral Guíu, "La repatriación de los niños del exilio: un intento de afirmación del régimen franquista, 1937-1939”, en J. Tusell et al. (eds.), El régimen de Franco. Política y relaciones exteriores (Congreso Internacional, Madrid, mayo 1993). Madrid: UNED, 1993, tomo I, pp. 341 -49; y A. Alted Vigil, "Le retour en Espagne des enfants évacués pendant la Guerre Civile espagnole: la Délégation extraordinaire au repatriement des mineurs (1938-1954)", en Enfants de la guerre civile espagnole. Vécus et répresentations de la gèneratios née entre 1925 et 1940. París: L'Harmattan/Fondation Nationale des Sciences Politiques/Centre d' Histoire de l'Europe du Vingtième Siècle (CHEVS), 1999, pp. 47-59. 
razas, de otras tradiciones familiares y espirituales, de otro régimen de vida, lejos, muy lejos del ambiente español. ${ }^{29}$

Frente a denuncias y críticas como ésta, no bastaba únicamente con difundir una buena imagen de la organización y desarrollo de las evacuaciones infantiles organizadas por el Gobierno de la República en el extranjero, sino que también había que intentar transmitir las bondades y maravillas de los países de acogida, a los que había que agradecer su solidaridad y ayuda para con la causa republicana. Este interés en dar a conocer las atenciones dispensadas a los niños, así como el cuidado y cariño con el que se les trataba, que les hacían sentirse como en casa en tierras extrañas, se materializó en distintas iniciativas entre las cuales las cartas fueron también protagonistas. Para el caso que nos ocupa sólo destacaré un par de ellas, reflejo de cómo la correspondencia de los Niños de Rusia fue empleada para la consecución de estos fines y convertida en objeto propagandístico por parte de ambos bandos, si bien sólo me referiré, por las características de la documentación manejada, a la propaganda republicana.

Una de esas iniciativas vino de la mano de los cuidadores y responsables de los niños en la URSS, personas que, en su mayoría, fueron a Rusia y formaron parte de las distintas expediciones infantiles porque pudieron demostrar su militancia republicana y su compromiso político-ideológico. ${ }^{30}$ Acompañar y cuidar a los niños evacuados era una manera más de colaborar con la causa, de luchar contra el fascismo. Una vez en Rusia, aparte de las autoridades soviéticas, estos

${ }^{29}$ Cómo trata la Nueva España a los niños de la zona roja. Pontevedra: Deputación Provincial de Pontevedra, 1937, pp. 2 y 7.

${ }^{30}$ De hecho, al poco de llegar a la URSS, y coincidiendo con la visita del inspector de Primera Enseñanza Antonio Ballesteros Usano, estos maestros y cuidadores tuvieron que escribir una pequeña biografía acompañada de un breve currículum donde debían hacer constar dicha militancia, expresar su voluntad de colaborar con el Gobierno y demostrar su experiencia docente, en el caso de los maestros, y laboral, en el caso de los cuidadores. Dichas notas biográficas se han conservado en el CDMH, PS Barcelona, caja 87, expediente 21. Las autobiografías del personal docente y auxiliar español que trabajó en las Casas de Niños y que no se han conservado en España se encuentran en el Archivo Estatal de la Federación Rusa de Moscú (AEFR), fondo A-307, catálogo 2, expediente 398. Sobre la visita del inspector Ballesteros a la URSS remito a V. Sierra Blas y M. ${ }^{a}$ M. Pozo Andrés, "Desde el paraíso soviético. Cultura escrita, educación y propaganda en las Casas de Niños españoles evacuados a Rusia durante la Guerra Civil española”, en R. Sani, J. Meda y D. Montino (dirs.), School Exercise Books. A Complex Source for a History of the Approach to Schooling and Education in the 19th and 20th Centuries. Florencia: Polistampa, 2010, vol. I, pp. 211-36. 
maestros y cuidadores debían responder a las órdenes de los miembros del Partido Comunista de España que se encontraban allí, pues eran éstos los que tenían la potestad sobre los evacuados, los que marcaban la pauta a seguir. El PCE, liderado entonces por Dolores Ibárruri, puso sus ilusiones en los menores españoles, a los que encomendó la tarea de convertirse en los futuros dirigentes del país cuando la guerra hubiera terminado. Por este motivo, los niños debían ser educados en el estilo de vida socialista y durante su estancia en la URSS tendrían que aprender a valorar las bondades y maravillas del "paraíso soviético". Sus cartas debían ser el reflejo de ese proceso formativo y de esa conciencia de admiración hacia todo lo soviético. Y así, una vez llegaran a España y fueran leídas por familias, amigos, vecinos y conocidos, servirían para difundir esa imagen idílica de la patria del proletariado, modelo de perfección y digna de imitación.

Respondiendo a estos objetivos, los maestros y cuidadores encargados de supervisar y corregir la correspondencia de los niños evacuados a Rusia no sólo se limitaron, como hemos visto antes, a dar el visto bueno a lo que los menores escribían, haciéndoles tachar o reescribir informaciones determinadas, sino que también procuraron que las cartas de los niños fueran transmisoras de esa pretendida imagen idílica de la URSS que las autoridades españolas y soviéticas querían difundir. Para ello intervinieron en la correspondencia infantil de muchas otras maneras.

Muchos se convirtieron en delegados o intermediarios gráficos. ${ }^{31}$ Dicha delegación o intermediación la llevaron a cabo de dos maneras: completa, es decir, escribieron las cartas en nombre de aquellos niños (normalmente los de menor edad) que no sabían escribir; o parcial, o sea, ayudaron a los menores que sí sabían escribir a redactar sus escritos, bien facilitándoles determinados modelos, fórmulas y esquemas, o bien dándoles consejos y sugiriéndoles temas e ideas. Esta labor de delegación se percibe en la documentación analizada al comprobar la homogeneidad textual y gráfica y la reiteración temática de las misivas, así como el estilo estereotipado que éstas presentan, pero igualmente queda reflejada en la aparición de distintas consignas y contenidos ideológicos que recorren los escritos (Fig. 3).

\footnotetext{
${ }^{31}$ Acerca de la delegación de escritura remito a A. Petrucci, "Escribir para otros", en id., Alfabetismo, escritura, sociedad. Barcelona: Gedisa, 1999, p. 106.
} 


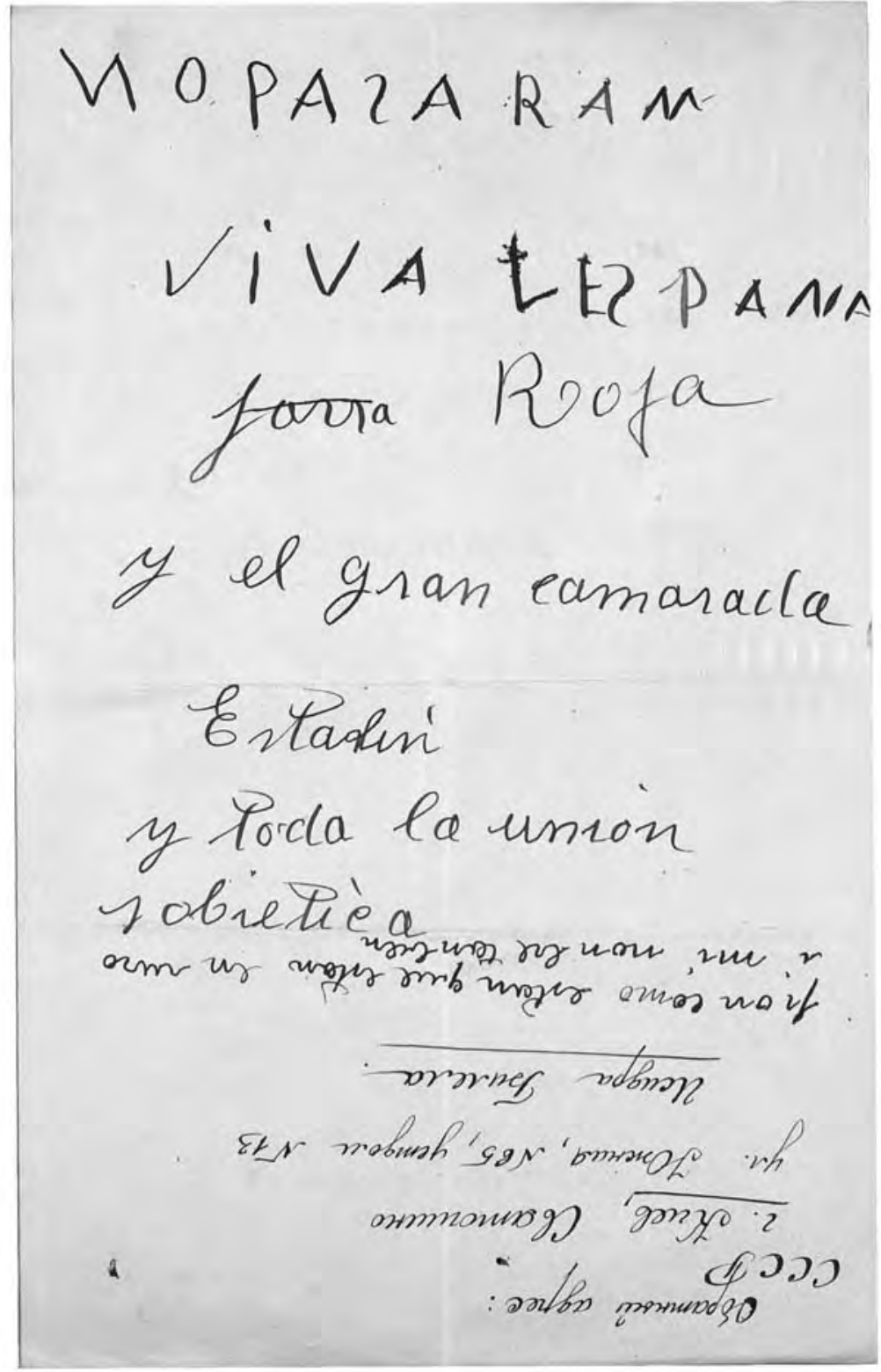

(Fig. 3)

Carta de Isidra Pilela dirigida a su hermano. [¿¿Kiev?], 25 de diciembre de 1937. Centro Documental de la Memoria Histórica de Salamanca, pieza Político-Social de Santander, serie "O", caja 51, carpeta 7, documento 19 (p. 2r). 
Todo ello hace que las cartas de los niños evacuados a Rusia, como las de los refugiados en otros países, deban ser leídas como el resultado de un proceso de asimilación y reelaboración por parte de los menores de ciertos contenidos y claves proporcionadas por los adultos que les rodearon:

Al llegar a la Unión Soviética nos recibieron como si fuésemos unos héroes que benimos de la guerra y hubiésemos hecho tremendas azañas.

[...] Así que ya ves que estoy muy contento en esta nación que es la patria de todos los trabajadores de todo el mundo. Padre, esta nación es la primera que se levantó y venció al tirano cruel y la vestia del fascismo será vencida por la España Roja, y así poco a poco irá cayendo la bestia fascista en todo el mundo, caerá para siempre y en todo el mundo reinará la igualdad y todos los obreros trabajarán y comerán, y en todo el mundo reinará la paz y la alegría.

Padre, en la Unión Soviética todos son iguales, tanto ingenieros como carpinteros, como mecánicos, como ferroviarios. Todos comen igual y trabajan igual, sean de la nacionalidad que sea[n], es como ruso como si es italiano igual. ${ }^{32}$

Junto a la delegación gráfica practicada por los adultos responsables de los niños evacuados, el otro ejemplo que quiero traer a colación a estas páginas tiene que ver con la prensa, pues ésta, tanto a nivel nacional como internacional, fue un espacio privilegiado para la difusión de los escritos infantiles. Los padres de los niños evacuados encontraron consuelo en las páginas de revistas y periódicos, donde habitualmente aparecieron reportajes acerca de la vida de los niños en los países de acogida ilustrados con fotografías y documentos de los propios menores. Testimonios valiosísimos, verdaderos tesoros, por cuanto constituyeron, en muchas ocasiones, las únicas narraciones del exilio infantil que llegaron de primera mano a España en los años de la contienda. Vinieron así a calmar la angustia de quienes habían visto partir a sus hijos hacia tierras extranjeras y de los que apenas habían tenido noticias, debido a la dificultad, como ya se ha señalado, de establecer contacto escrito y a la irregularidad del correo propia de las circunstancias.

${ }^{32}$ Carta de Emiliano Aza dirigida a su padre y hermanos. Odessa, 31 de enero de 1938. CDMH, PS Santander, serie "O", caja 51, carpeta 7, documento 6. 
Pero no nos engañemos. Más allá de esta función terapéutica que tuvo para los progenitores la publicación de los escritos infantiles en letras de imprenta, debemos tener en cuenta que las cartas de los niños fueron, al igual que los dibujos o las fotografías, ${ }^{33}$ un importante recurso emocional para solicitar ayuda material o económica a otros países, denunciar las atrocidades del enemigo y ganar el apoyo de la opinión pública. Su publicación no respondía a otro fin más que a ése: convertir estos escritos en punto de mira, mostrar a partir de ellos el buen estado de los niños evacuados, la bondad de la República para con los menores y la generosidad de los países de acogida que, con este gesto, apoyaban la causa republicana. Las cartas que se publicaron en la prensa fueron especialmente seleccionadas de entre el resto por su emotividad y su capacidad de impresionar a los lectores. Muchas fueron manipuladas, recortadas o ampliadas sirviendo a muy diversos intereses publicitarios y a los criterios de edición.

Una de las publicaciones periódicas que más espacio dedicó a la evacuación de los Niños de Rusia fue El Magisterio Español, revista dedicada a los docentes, que durante la contienda se editó primero en Valencia y después en Barcelona. Los numerosos reportajes y entrevistas sobre Rusia y los niños españoles allí evacuados vienen a demostrar cómo los maestros de aquel momento estaban interesados en la forma de vida y la organización de la enseñanza en aquél país. De entre las páginas que El Magisterio Español dedicó a este tema son especialmente representativas las que tienen como protagonista a Margarita Churruca.

La entrevista a Margarita Churruca fue publicada en julio de 1938. En ella, la protagonista cuenta cómo tuvo que abandonar su ciudad natal, San Sebastián, a sus 78 años, acompañada de sus hijos y sus dos nietos, Miren y Eustaquio, de 12 y 9 años respectivamente. Éstos fueron evacuados a la URSS en cuanto hubo

33 Sobre el uso propagandístico de los dibujos y escritos de los niños remito a La guerra de España dibujada por sus niños, Barcelona/París: Equipo al Servicio de la Infancia Amenazada, 1938; J. A. Weissberger, They Still Draw Pictures. A Collection of Sixty Drawings Made by Spanish Children during the War. Nueva York: Oxford UP, 1939; A. Brauner y F. Brauner, Dessins d'enfants de la Guerre d'Espagne. Saint-Mandé: Expansion Scientifique Française (GRPE), 1976; Children's Drawings of the Spanish Civil War. A Collection of 153 Drawings by Children Living in Refugee Colonies during the War. Nueva York: Schneidereith \& Sons/The Spanish Institute, 1986; A pesar de todo dibujan; y J. Meda, "Propaganda mano libera. I disegni dei bambini spagnoli durante la Guerra Civile”, Storie in Movimento. Rivista di Storia della Conflittualità Sociale, 10 (2006), pp. 74-81. 
oportunidad, para que no tuvieran que padecer — afirma la abuela— "los criminales bombardeos de la aviación fascista”. Desde que los niños se marcharon (en el momento de realizarse la entrevista residían en la Casa de Niños de Obninskoe), Margarita no dejó de escribirles, a pesar de los continuos cambios de residencia y de su salud debilitada. Gustaba de enviarles largas cartas y de leer una y otra vez las que ellos le mandaban. Pero, un día, sin más, dejó de recibir cartas de sus nietos. Desesperada ante la falta de noticias, Margarita decidió ponerse manos a la obra para saber algo de ellos y escribió, en secreto, al mismísimo Stalin: "Yo tenía la certeza absoluta de que Stalin, el gran padre de los trabajadores, tan amante de los niños, comprendería el anhelo de esta viejecita y me contestaría". Así fue. Un buen día llegó una carta de Moscú firmada en nombre del camarada Stalin por "Krijianski y Semenov, directores de las casas infantiles y de las escuelas especiales del Comisariado de Instrucción Pública de la RSFSR [República Socialista Federativa Soviética de Rusia]". Junto a su carta, en la que los responsables rusos le daban noticias detalladas de los niños, se adjuntaban, además, una fotografía y otra misiva de éstos:

Moscú, 28 de abril de 1938.

Querida e inolvidable abuelita: Salud. Estas cuatro letras sirven para decirte que el camarada Stalin recibió tu carta y ha mandado a un miembro de la Comisión para que nos vea. Aquí estamos muy bien y ya nos estamos preparando para la gran fiesta del Primero de Mayo, tan amada por todo el proletariado español. Ahora estamos haciendo el periódico y muchas cosas más. Tatín se acuerda mucho de ti y me encarga que te mande de su parte muchos besos y abrazos y lo mismo para todos los de casa. Aquí nos tienen y nos tratan como a verdaderos hijos: nos quieren mucho y por eso les debemos nuestro agradecimiento por lo que hacen por nosotros. Sin más se despiden tus nietecitos, que mucho te quieren y no te olvidan y desean verte pronto.

¡Viva Rusia y todos los camaradas rusos y toda la URSS!

¡Viva Stalin, tan querido por todo el mundo! ¡Viva, viva! ${ }^{44}$

34 “Los niños españoles en la URSS. Una viejecita vasca de 78 años que escribió a Stalin", El Magisterio

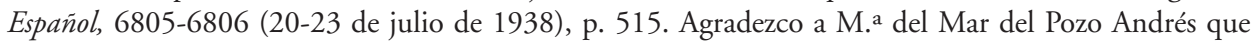
me señalara la existencia de este reportaje. 


\subsection{Pruebas para la represión}

Por último, dentro de estos silencios que pueden reconstruirse en las cartas de los niños evacuados a la Unión Soviética y que tan imprescindibles de conocer son para poder estudiarlas e interpretarlas correctamente, quiero incidir en un último aspecto que se relaciona con las políticas de conservación. ¿Cómo fueron a parar las cartas que los Niños de Rusia escribieron durante su exilio a sus familiares al Centro Documental de la Memoria Histórica de Salamanca? ¿Qué implica que se hayan conservado ahí? ¿Por qué el hecho de ir a parar a dicho archivo supuso una transformación de las misivas en lo que a sus objetivos y fines se refiere?

Con la caída de Barcelona, toda la documentación que se había acumulado desde el inicio de la contienda en los distintos organismos republicanos que tuvieron allí su sede, incluidos el Negociado de Censura y la Delegación de Asistencia Social de Euzkadi, como había ocurrido ya tras la toma de otras ciudades importantes, pasó a manos de Franco. Por Orden de 20 de abril de 1937 éste había creado la llamada Oficina de Información y Propaganda Anticomunista (OIPA), que junto a la Delegación de Asuntos Especiales (DEA), dedicada a la propaganda anti-masónica desde el 29 de mayo de ese mismo año, dependía del Ministerio del Interior. Ambos organismos se fusionaron, una vez nombrado el primer Gobierno de Franco, por Orden de 26 de abril de 1938, en la llamada «Delegación para recuperar, clasificar y custodiar la documentación procedente de personas y entidades del bando republicano» (DERD), dirigida por Marcelino de Ulibarri. ${ }^{35}$

Para conseguir sus propósitos, y a medida que las tropas franquistas iban conquistando territorios, el Servicio de Recuperación de Documentos (SRD), médula espinal de la DERD, se encargó de incautar todo papel que los republicanos en retirada olvidaron destruir o no pudieron llevarse consigo. ${ }^{36}$ Concretamente, en el caso de Barcelona, el SRD practicó, entre el 28 de enero y el 3 de julio de 1939, un total de 1399 registros en instituciones, partidos, sindicatos,

35 S. Michonneau, "Les papiers de la guerre, la guerre des papiers. L affaire des archives de Salamanque", Sociétés et Représentations, 19 (2005), pp. 250-67 (en particular, p. 251).

${ }^{36}$ J. M. ${ }^{a}$ Figueres, "La guerra del paper", J. Ferrer, J. M. a Figueres y J. M. Sans i Travé, en Els papers de Salamanca. Història d'un botí de guerra. Barcelona: Llibres de 1 Índex, 1996, pp. 71-191. 
asociaciones, editoriales, periódicos y domicilios particulares. El botín fue sorprendente: en julio de 1939 un tren de 12 vagones trasladó de Barcelona a Salamanca 130 toneladas de documentos. ${ }^{37}$

Una gran parte de los documentos incautados tras la toma del territorio que había estado en manos de los republicanos durante la Guerra Civil fue a parar al Convento de San Ambrosio, en la ciudad de Salamanca, donde pasó a disposición del Tribunal Especial para la Masonería y el Comunismo. ${ }^{38}$ Entre estos documentos robados estaban también las misivas de los niños evacuados a Rusia. Las cartas, que todavía no habían podido ser entregadas a sus destinatarios, bien por no haber encontrado manera de dar con los mismos o bien por la imposibilidad de despachar con rapidez el gran volumen de correspondencia existente, fueron depositadas, al finalizar la contienda, junto al resto de correspondencia requisada y recibida desde el extranjero que las tropas de Franco encontraron en sus registros, en el Cuartel General del Generalísimo, sito también en Salamanca, donde estaba ubicado el Gabinete de Censura de Correspondencia extranjera, y desde allí fueron trasladadas al convento antedicho. ${ }^{39}$

El Convento de San Ambrosio fue así el germen del Archivo General de la Guerra Civil de Salamanca, que desde finales de 1979 pasó a formar parte, como una delegación independiente, del Archivo Histórico Nacional de Madrid, y que actualmente está integrado, por Real Decreto de 1 de junio de 2007, en el Centro Documental de la Memoria Histórica. A este depósito documental, por tanto, fueron a parar, junto a miles de documentos incautados, todas las cartas que se consideraron susceptibles de aportar información acerca de todas aquellas personas que por un motivo u otro, y en muy diversos grados, se habían significado por su conducta y actuación políticas durante la contienda sirviendo al bando republicano y a las ideas que éste defendió en los campos

37 J. B. Culla y B. de Riquer, "Sobre l' Arxiu de Salamanca: algunes precisions i reflexions", L'Espill, 13 (2003), pp. 72-85.

38 J. Ferrer, "La lluita parlamentària per la devolució", en id. et al., Els papers, p. 13. Para más información acerca de los orígenes del Archivo General de la Guerra Civil de Salamanca, hoy Centro Documental de la Memoria Histórica, remito a A. Bernals, M. Casademont y A. Mayans, La Documentaciò catalana a Salamanca: un estat de la questio, 1936-2003. Barcelona: Associaciò d Arxivers de Catalunya, 2003; así como a J. Cruanyes, Els papers de Salamanca. L'expoliaciò del patrimoni documental de Catalunya (1938-1939). Barcelona: Edicions 62, 2003.

${ }^{39}$ García Sánchez: "La correspondencia”, p. 330. 
de batalla durante los tres años de guerra. Las cartas y muchos otros documentos personales y oficiales formaron, por tanto, parte del aparato represivo franquista, siendo empleados como pruebas con las que inculpar a los sospechosos.

Eso explica que las cartas de los Niños de Rusia estén subrayadas a conciencia y contengan anotaciones de quienes se encargaron de leerlas exhaustivamente y recopilar de esa lectura información, especialmente datos referidos a sus autores, sus destinatarios y todas las personas que apareciesen citadas en las misivas. El motivo por el que éstas y otras cartas personales se encuentran hoy en el que muchos llaman el "archivo de la represión" no es otro que el de haber sido consideradas, por tanto, como material subversivo y utilizadas para localizar y perseguir a personas relacionadas, con motivo o sin él, con la causa republicana.

Las cartas que los niños evacuados a la Unión Soviética escribieron a sus padres durante esos dos primeros años de su estancia, en 1937 y 1938, forman parte, así, del conjunto documental que Franco fue reuniendo durante la guerra y en la inmediata posguerra a medida que fue tomando posiciones y avanzando en la victoria. Todo ello respondía a una estrategia clara y premeditada: poder reunir el mayor volumen de información posible para, una vez terminada la contienda, acabar definitivamente con cualquier vestigio de disidencia y con todos aquellos que desde el día del levantamiento militar se habían mostrado desafectos al mismo y, por tanto, a su régimen.

\section{CODA}

Por todos estos silencios que contienen las cartas infantiles enviadas desde Rusia, así como otros documentos del exilio infantil español que se conservan en el Centro Documental de la Memoria Histórica de Salamanca y en otros archivos públicos y privados, debemos analizarlas con sumo cuidado antes de proceder a su edición y estudio, si no queremos errar en nuestra interpretación. Su historia, como todas las historias, va mucho más allá de lo que a simple vista podemos intuir. Mucho más allá del hecho de que unos niños que estaban en un país extraño mientras la guerra asolaba el suyo sintieran la necesidad y la obligación de escribir a casa.

De documentos privados y personales, las cartas pasaron a convertirse en documentos públicos, al ser leídas primero por personas no invitadas a su lec- 
tura, como los responsables de los menores y los censores, y después editadas en la prensa y otras publicaciones periódicas con fines propagandísticos. Y aún más. De documentos concebidos para tranquilizar y consolar, las cartas de los Niños de Rusia acabaron siendo pruebas para condenar a los implicados en la relación epistolar. Sus autores nunca podrían haber imaginado que escribiéndolas estaban, sin querer, contribuyendo a la persecución y al castigo de los suyos.

Las intervenciones de los adultos que les rodearon, las condiciones en que estos documentos se produjeron y los caminos que los mismos siguieron hasta llegar al que hoy es su lugar de conservación, son aspectos que su lectura sin más no nos da, aspectos que debemos ser capaces de encontrar leyendo entre líneas y desvelando lo que no está escrito. Porque sólo de esa manera podremos reconstruir realmente lo acontecido. Y porque sólo reconstruyendo lo acontecido podremos hacer posible que el verso de Pedro Garfias no siga hoy teniendo vigencia. Que el país que entonces vio cómo aquellos niños lo abandonaron para poder sobrevivir, no vuelva a perderlos ahora y los tenga presentes, siempre, en su memoria. 